\title{
Cephalometric Analysis for Gender Determination Using Maxillary Sinus Index in Population of Gujrat, India
}

\author{
Arjun Kundu ${ }^{1}$, Dhwani Patel ${ }^{1 *}$, Dharmesh Silajiya ${ }^{2}$ \\ ${ }^{1}$ Department of Forensic Odontology, School of Forensic Science, National Forensic Sciences University, Gandhinagar, Gujarat. India \\ ${ }^{2}$ School of Forensic Science, National Forensic Sciences University, Gandhinagar, Gujarat, India.
}

\begin{abstract}
Introduction: Humans are sexually dimorphic. Identification of remnants of skeletal and decomposing parts of humans is one of the most difficult skills in forensic medicine. Forensic anthropologists can receive whole or fragmented skeletal remains. But the unique thing is that the maxillary sinus is intact within the skull, so maxillary sinus radiography is being used to identify remains and determine gender.
\end{abstract}

Materials and Method: A total of 51 adult digital lateral cephalometric radiographs (20 males and 31 females) were included in the study. The maxillary sinus analysis was performed by measuring the height and width of these digital lateral cephalometric radiographs using measurement tools of Sidexis4 software. Maxillary sinus index was calculated, discriminant function analysis performed, and discriminant equation derived for determination of gender.

Results: Comparison of maxillary sinus parameters (height and width) between male and female groups showed statistically insignificant differences in this study. Regression analysis is done and an equation is derived, which will aid in the prediction of gender by substituting the values of specific measurements in the equation.

Keywords: Anthropology, Cephalometric analysis, Gender Determination, Maxillary Sinus

Int J Eth Trauma Victimology (2021). DOI: 10.18099/ijetv.v7i02.2

\section{INTRODUCTION}

$\mathrm{H}^{2}$ umans are sexually dimorphic. The identification process of any skeletal remains and decomposing parts of humans is one of the most difficult aspects of forensics. For gender determination in unidentified remains, the foremost choice is the innominate bones, including skull, pelvis, long bones with an epiphysis and a metaphysis, the sella turcica, foramen magnum, length and the height of the head, the distance between the basion and the nasion, the head circumference, the supraorbital edge length, the mastoid process, the mandibular ramus, the height of the mandibular symphysis, the shape and the length of the palate, the circumference of the occipital condyle, sizes of the teeth and paranasal sinuses. ${ }^{1,2}$ In maximum cases, like disaster victim identification, the bodies found are not in proper anatomy; often, fragments of the skeletal remains can lead to difficulty in identifying the deceased. But the unique thing is that the maxillary sinus mostly remains intact within the skull so maxillary sinus radiography is being used for identification and is a great tool for gender determination. If we go back to the development of the maxillary sinus, its anatomy shows many variations. Maxillary sinuses are two spaces, filled with air located in the maxillary bone and can be of varied sizes and shapes. The walls are thin in them. We discuss the apex extending inside the zygomatic process and settling in the zygomatic bone. The floor comprises the alveolar process, the first, the second, and the third molars, and the canines' roots may perforate the floor. ${ }^{3}$ The pneumatization of the maxillary sinus is different for everyone, and its volume depends upon age. ${ }^{4}$ Frontal sinuses are unique to each individual due to their morphological structures, and in forensic science, taking (CIJETV. All rights reserved
Corresponding Author: Dhwani Patel, Assistant Professor, Laboratory of Forensic Odontology, School of Forensic Science, National Forensic Sciences University, Gandhinagar, Gujarat-382007, India, e-mail: dhwani.patel@nfsu.ac.in

How to cite this article: Kundu A, Patel D, Silajiya D. Cephalometric Analysis for Gender Determination Using Maxillary Sinus Index in Population of Gujrat, India. Int J Eth Trauma Victimology. 2021;7(2):6-9.

Source of support: Nil

Conflict of interest: None

Received:24/12/2021;

Accepted: 29/12/2021;

Received in revised form: $28 / 12 / 2022$ Published: 20/01/2022

advantage of these features is very important for personal identification. ${ }^{5-7}$ The maxillary sinus is one of the paranasal sinuses' largest sinuses. ${ }^{8}$ Its development begins at the $3 \mathrm{rd}$ month of the fetal development from the infundibulum of the ethmoid bone. ${ }^{9}$ After continuation with birth it expands laterally during the two growth spurt periods (from birth to 3 years of age and from 7 to 12 years). ${ }^{10}$ However, the mandibular growth remains well after the further ages and outstretch its final dimensions at the age of 20 years in males and 18 years in females. ${ }^{11}$ This study is designed to determine the accuracy and reliability of maxillary sinus dimensions as a method for gender identification of unknown persons.

\section{Material and Methods}

A total of 51 lateral cephalograms belonging to both genders (20 males and 31 females) of age group 17-47 years were selected for the study. The radiographs were then stored with 
incorporated patients' details. All radiographs were interpreted, and the maxillary sinuses' height and width were measured using Sidexis4 next-generation software (version 4, Sirona, Germany). The maxillary sinus index (MSI) is calculated as MSI = maxillary sinus width/height (Figure 1$)$. The results obtained were subjected to statistical analysis using SPSS version 20 (statistical package for social sciences) software.

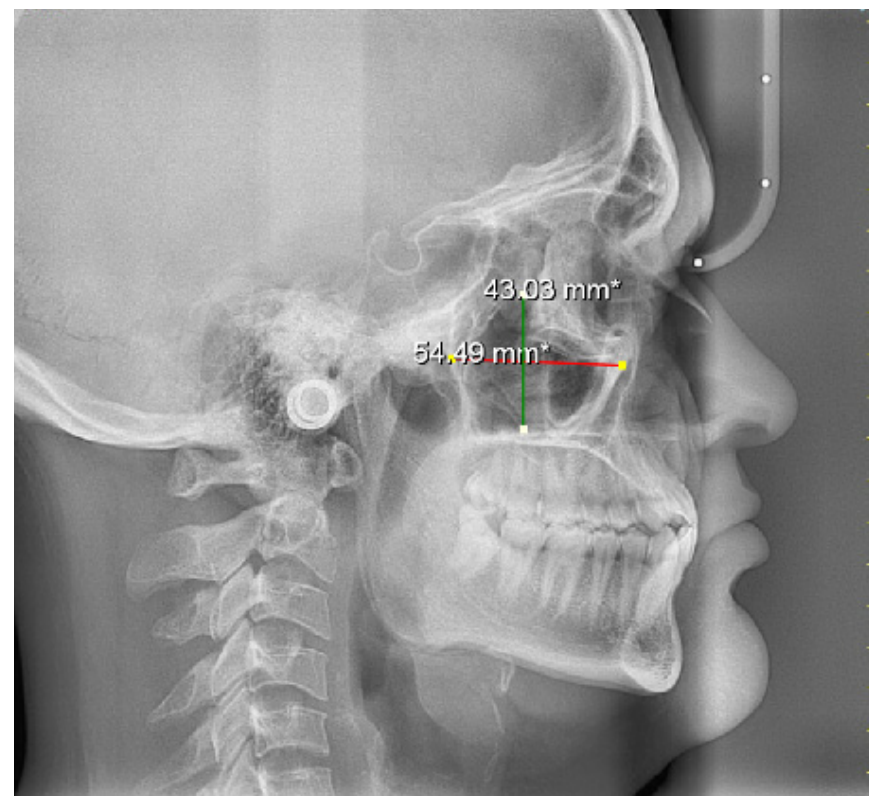

Figure 1: Measurement of the maxillary sinus height and width
The mean values and standard deviation of the maxillary sinus height, width, and MSI in males and females were obtained and tabulated using an independent t-test (Table 1). Significance level was based on $p$ value $<0.05$.

\section{Results}

Analyzing the obtained data, the result shows that the mean maxillary sinus height is $49.9 \mathrm{~mm}$ in males and $50.9 \mathrm{~mm}$ in females, and it is statistically insignificant with $p$ value of 0.69 . The mean maxillary sinus width is $44.01 \mathrm{~mm}$ in males and $44.12 \mathrm{~mm}$ in females and it is statistically insignificant with $p$ value of 0.59 . The mean MSI is higher in females (1.16) when compared with males (1.13) with an insignificant $p$-value of 0.244 (Table 2).

Regression analysis is done and an equation is obtained as follows (Table 3):

$$
\mathrm{R}=1.217+0.338 \times \mathrm{MSI} \text {. }
$$

This equation is provided to calculate " $R$ " which will aid in the prediction of gender by substituting the values of specific measurements (MSI) in the equation. A greater calculated "R" value near to "2" indicates female gender, while "R" value near to "1" indicates male gender.

\section{Discussion}

Identification from remains of human skeletons is an important forensic procedure, and determining age and gender is an integral part of identification. The current study is designed

Table 1: Independent Sample Test.

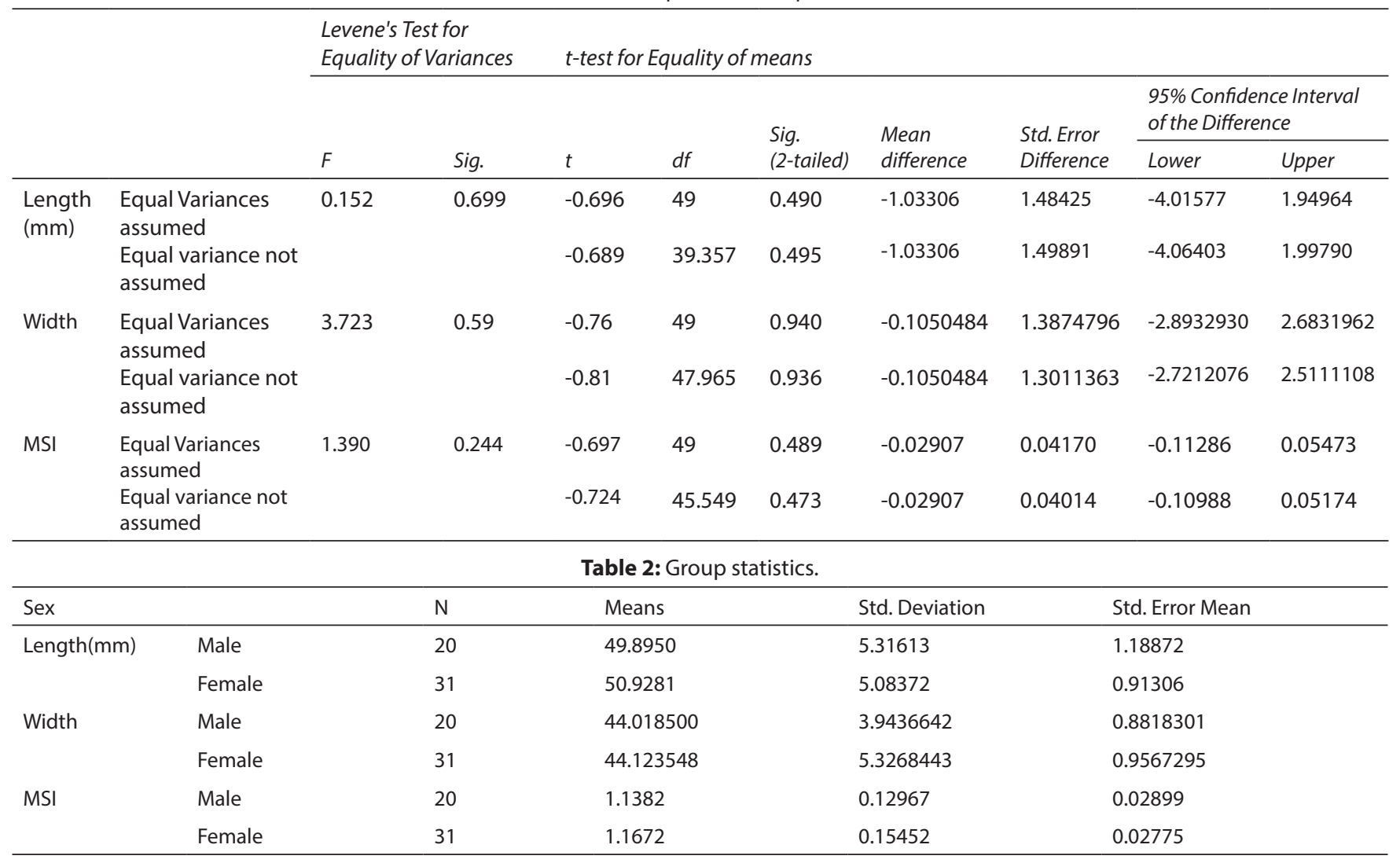


Cephalometric Analysis for Gender Determination using Maxillary Sinus Index

\begin{tabular}{|c|c|c|c|c|c|c|}
\hline \multicolumn{7}{|c|}{ Coefficients $^{a}$} \\
\hline \multirow[b]{2}{*}{ Model } & & \multicolumn{2}{|c|}{ Unstandardized Coefficients } & \multirow{2}{*}{$\begin{array}{l}\text { Standardized Coefficients } \\
\text { Beta }\end{array}$} & \multirow[b]{2}{*}{$t$} & \multirow[b]{2}{*}{ Sig. } \\
\hline & & $B$ & Std. Error & & & \\
\hline \multirow[t]{2}{*}{1} & (Constant) & 1.217 & .564 & & 2.157 & .036 \\
\hline & MSI & .338 & .485 & .099 & .697 & .489 \\
\hline \multicolumn{7}{|c|}{ a. Dependent Variable: Sex } \\
\hline
\end{tabular}

to analyze gender-based differences in maxillary sinus dimensions. Comparison of maxillary sinus parameters (height and width) between male and female groups showed statistically insignificant differences in this study. A study conducted by Saccucci et al. on gender determination using maxillary sinus concluded that no statistical difference was found in maxillary sinus volumes between genders. Their study rejects the hypothesis that maxillary sinus morphology is crucial to determine gender, ${ }^{12}$ which supports our study results. Conversely to our study results, Uthman et al. concluded that CT images could be used for sex determination and their study proved that the maxillary sinus exhibits anatomic variability with a significant sex difference concerning maxillary sinus width, length, and height and among these parameters, the left maxillary sinus height was the best discriminate variable. ${ }^{13}$ Based on the results of Sheikh et al., maxillary sinus height and width exhibit anatomic variability between genders but without any significant difference. The width of the left maxillary sinus can be used as the best discriminate parameter to study sexual dimorphism with an accuracy of 59\%. ${ }^{14}$ According to Urooge et al., the accuracy level for the left maxillary sinus width was $60 \%$ in determining gender. ${ }^{15}$ Azhar et al. showed that maxillary sinus length was the best discriminant parameter with an overall accuracy of $69.81 \%$ in the determination of gender. ${ }^{16}$ A study was done by Sharma SK et al. to measure Maxillary Sinus volume and dimensions by CT scan for gender determination. The difference was statistically significant for sinus anterior-posterior dimension (length) and volume. The Maxillary Sinus length was the best discriminant parameter with an overall accuracy of $69.81 \%{ }^{17}$ Maxillary Sinus is the first paranasal sinus to form, and its development has been documented as early as the 17 th week of the prenatal period. However, it is after birth that the majority of growth occurs. ${ }^{18,19}$ The Maxillary Sinuses are complex anatomical structures with significant variations between individuals. ${ }^{20}$ The study of Kim et al. on the three-dimensional reconstruction and simulation of maxillary sinus showed that its morphology and size are variable. ${ }^{21}$ Morphological variability plays an important role. The differences in growth and development are genetically determined, but the morphological features are also affected by environmental modifications. ${ }^{22}$ Paranasal sinuses and pneumatic bones decrease after reaching their maximal size. ${ }^{23-25}$ According to Jun et al., before the sinus volume declines, the maxillary sinuses of males reach their maximum volume at $21-30$ years and women at 11-20 years. The decrease of the maxillary sinus volume may be caused by the loss of bone matrix in the surrounding bones due to aging. ${ }^{26}$ Spaeth et al. said that the termination of expansion of maxillary sinus is fixed at 17 years of age (same for both sexes). ${ }^{27}$ Schatz et al. observed that maxillary sinus increases in volume for up to 15 years, afterward maintaining similar volume. ${ }^{28}$

\section{Conclusion}

Gender determination is one of the integral aspects of personal identification of an unidentified cadaver, thus narrowing down the diagnosis to be more accurate. Most of the bones conventionally used (skull, pelvis, long bones with an epiphysis and a metaphysis, the sella turcica, foramen magnum, length and the height of the head, the distance between the basion and the nasion, and the distance between the basion and the prosthion, the circumference of the head, the length of the supraorbital edge, the mastoid process, the mandibular ramus, the height of the mandibular symphysis, the shape and the length of the palate, the circumference of the occipital condyle, sizes of the teeth and paranasal sinuses.) are often recovered either in a fragmented and/or decomposed state, especially in catastrophes and mass disasters, making identification difficult. Various authors have reported that zygomatic bones and maxillary sinus remain intact although the skull and other bones may be badly disfigured in incinerated victims. ${ }^{29,30}$ Lateral cephalometry, a two-dimensional conventional radiographic technique, is readily available and inexpensive and provides a good assessment of the soft tissue and the hard tissue elements that define the paranasal sinuses and their surrounding structures. Therefore, the morphometric analysis of the maxillary sinus has been proved to be a valuable tool in assessing sexual dimorphism. However, further studies are desirable on large sample size.

\section{ACKnowledgement}

I would also like to show my gratitude to Dr. Kalgi Shah for her support in the study.

\section{REFERENCES}

1. Bangi BB, Ginjupally U, Nadendla LK, Vadla B. 3D evaluation of maxillary sinus using computed tomography: A sexual dimorphic study. International journal of dentistry. 2017 Apr 4;2017. https:// doi.org/10.1155/2017/9017078.

2. Yasar, Hacer\& Duran, Semra\&Canturk, Nergis\&Canturk, Gurol. (2007). Determination of gender by measuring the size of the maxillary sinuses in computed tomography scans. Surgical and radiologic anatomy: SRA. 29. 9-13. 10.1007/s00276-006-0157-1.

3. Teke HY, Duran S, Canturk N, Canturk G. Determination of gender by measuring the size of the maxillary sinuses in 
computerized tomography scans. Surgical and radiologic anatomy. 2007 Feb 1;29(1):9-13.. [PubMed: 17171233]

4. Abdulhameed A, Zagga AD, Maaji SM, Bello A, Bello SS, Usman $\mathrm{JD}$, et al. Three-dimensional volumetric analysis of the maxillary sinus using computed tomography from UsmanuDanfodiyo University Teaching Hospital, Sokoto, Nigeria. Int J Health Med Inf. 2013; 2:1-9.

5. Kiran CS, Ramaswamy P, Khaitan T. Frontal sinus index - A new toolfor sex determination. J Forensic Radiol Imaging 2014; 2:77-9.

6. Guevara YV, Watanabe N, Yamaki M, Saito I. The frontal sinus enlargement as an indicator of growth maturity in class III patients - A pilot study. Int J Med Sci Public Health 2013; 2:451-5.

7. Buyuk SK, Karaman A, Yasa Y. Association between frontal sinus morphology and craniofacial parameters: A forensic view. 2017; 49:20-23. doi: 10.1016/j.jflm.2017.05.007.

8. Emirzeoglu M, Sahin B, Bilgic S, Celebi M, Uzun A. Volumetric evaluation of the paranasal sinuses in normal subjects using computer tomography images: A stereological study. Auris Nasus Larynx 2007; 34:191-5.

9. Scuderi AJ, Harnsberger HR, Boyer RS. Pneumatization of the interpretation of CT scans and MR images. AJR Am J Roentgenol1993; 160:1101-4.

10. Urabi AH, Al-Nakib LH. Digital lateral cephalometric assessment of maxillary sinus dimensions in different skeletal classes. J Univ Baghdad 2012; 24:35-8.

11. Salehi P, Heidari S, Khajeh F. Relationship between frontal sinus surface area and mandibular size on lateral cephalograms of adults. J Isfahan Dent Sch 2012; 8:244-50.

12. Saccucci M, Cipriani F, Carderi S, Di Carlo G, D'Attilio M, Rodolfino D, Festa F, Polimeni A. Gender assessment through three-dimensional analysis of maxillary sinuses by means of cone beam computed tomography. Eur Rev Med Pharmacol Sci. 2015 Jan 1;19(2):185-93.

13. Uthman AT, AL-Rawi NH, AL-Naaimi AS, AL-Timimi JF. Evaluation of maxillary sinus dimension in gender determination using helical CT scanning. J Forensic Sci 2011; 56: 403-408.

14. Sheikh NN, Ashwinirani SR, Suragimath G, Shiva Kumar KM. Evaluation of gender based on the size of maxillary sinus and frontal sinus using paranasal sinus views radiographs in Maharashtra population, India. J Oral Res Rev 2018; 10:57-61.

15. Urooge A, Patil BA. Sexual dimorphism of maxillary sinus: A morphometric analysis using cone beam computed tomography. J Clin Diagn Res 2017;11: ZC67-70.

16. Azhar A, Ibrahim G, Salah F. Ct scan images analysis of maxillary sinus dimensions as a forensic tool for sexual and racial detection in a sample of Kurdish population. Eur Sci J 2015; 11:271-81.

17. Sharma SK, Jehan M, Kumar A. Measurements of Maxillary Sinus Volume and Dimensions by Computed Tomography Scan for Gender Determination. JASI. 2014;63(1):36-42.
18. Scuderi AJ, Harnsberger HR, Boyer RS. Pneumatization of the paranasal sinuses: normal features of importance to the accurate interpretation of CT scans and MR images. AJR. American journal of roentgenology. 1993 May;160(5):1101-4.

19. Farah G, Nafis AF. Morphometric analysis of developing maxillary sinuses in human foetuses. Int J Morphol. 2006;24(3): 303-8.

20. Sahlstrand-Johnson P, Jannert M, Strömbeck A, Abul-Kasim K. Computed tomography measurements of different dimensions of maxillary and frontal sinuses. BMC medical imaging. 2011 Dec;11(1):1-7. http://dx.doi.org/10.1186/1471-2342-11-8.

21. Kim HJ, Yoon HR, Kim KD, Kang MK, Kwak HH, Park HD, Han SH, Park CS. Personal-computer-based three-dimensional reconstruction and simulation of maxillary sinus. Surgical and Radiologic Anatomy. 2002 Dec;24(6):392-8.

22. Wolf G, Anderhuber W, Kuhn F. Development of the paranasal sinuses in children: implications for paranasal sinus surgery. Annals of Otology, Rhinology \& Laryngology. 1993 Sep;102(9):705-11.

23. P. Reittner, O. Doerfler, T. Goritschnig, M. Tillich, W. Koele, H. Stammbereger, et al. Magnetic resonance imaging patterns of the development of the sphenoid sinus: a review of 800 patients. Rhinology 38 (2001) 121-124.

24. Vidic B, STOM D. The postnatal development of the sphenoidal sinus and its spread into the dorsum sellae and posterior clinoid processes. American Journal of Roentgenology. 1968 Sep;104(1):177-83.

25. Yonetsu K, Watanabe M, Nakamura T. Age-related expansion and reduction in aeration of the sphenoid sinus: volume assessment by helical CT scanning. American journal of neuroradiology. 2000 Jan 1;21(1):179-82.

26. Jun BC, Song SW, Park CS, Lee DH, Cho KJ, Cho JH. The analysis of maxillary sinus aeration according to aging process; volume assessment by 3-dimensional reconstruction by highresolutional CT scanning. Otolaryngology-Head and Neck Surgery. 2005 Mar;132(3):429-34.

27. Spaeth J, Krügelstein U, Schlöndorff G. The paranasal sinuses in CT-imaging: development from birth to age 25. International journal of pediatric otorhinolaryngology. 1997 Feb 14;39(1): 25-40.

28. Schatz CJ, Becker TS. Normal CT anatomy of the paranasal sinuses. Radiologic Clinics of North America. 1984 Mar 1;22(1):107-18.

29. Kanthem RK, Guttikonda VR, Yeluri S, Kumari G. Sex determination using maxillary sinus. Journal of forensic dental sciences. 2015 May;7(2):163.

30. Attia AM, El-Badrawy AM, Shebel HM. Gender identification from maxillary sinus using multi-detector computed tomography. Mansoura Journal of Forensic Medicine and Clinical Toxicology. 2012 Jan 1;20(1):17-28. 